\title{
Uncanny spaces for higher education: teaching and learning in virtual worlds
}

Siân Bayne*

University of Edinburgh, Edinburgh, UK

(Received 7 April 2008; final version received 8 September 2008)

This paper brings together the theory of the uncanny as it emerges in cultural theory, with an understanding of the uncanniness and troublesomeness seen to be inherent in certain understandings of teaching and learning in higher education. Drawing on research into students' experiences of learning in virtual worlds, it explores the sense in which teaching in such spaces materialises and extends the positive aspects of uncertainty, strangeness, disquietude and troublesomeness in online higher education.

Keywords: virtual world; second life; uncanny

\section{Introduction}

Avatars are nothing but corpses. So, somebody comes along and will fill those dead corpses with something that is believed to be identity or feelings? For me they are artificially normed identities, perhaps even desires... (Eleanor, weblog posting) ${ }^{1}$

Students immersed in Second Life and other virtual worlds quite regularly describe such environments in terms of their 'deathliness', their blurring of the boundary between fantasy and reality, and their foregrounding of issues to do with identity which move beyond the weird ontology of the avatar to the nature of being as a learner across the digital and material domains. Such concerns connect directly with the theme of 'uncanniness' which this paper will explore.

The theory of the uncanny has gained a new significance in the last few decades, with a resurgence of interest in the theme in literary and cultural theory (for example Kristeva 1991; Castle 1995; Arnzen 1997; Grenville 2002; Tie 2004), robotics (Mori 1970; Ramey 2005) and technology studies (for example Johnson 1999; Weight 2006). There are few explicit examples of its application in education, however, with Carrington (2005) being an important exception.

Here, I will draw together insights from students who are actively using virtual worlds as learners, with a theoretical framework drawn largely from Freud's (1919/2003) understanding of the nature of the uncanny. I will then extend this into a discussion of the nature of higher education (HE), drawing on Barnett's $(2005,2007)$ concern with the 'ontological shift' in HE, and on other constructions of higher education which emphasise the necessity of its troublesomeness (Perkins 2006; Meyer and Land 2005, 2006) and its immersion of learners in productive states of uncertainty (Royle 2003). I will end by suggesting that

*Email: sian.bayne@ed.ac.uk 
Second Life and other virtual worlds may function as spaces where a positive "pedagogy of uncertainty' (Barnett 2007, 137) may be explored and conducted by learners and teachers in higher education.

\title{
Method
}

Some of the research data presented here are drawn from a Higher Education Academyfunded project which conducted a virtual ethnography of three formal courses in higher education which were using social networking technologies. ${ }^{2}$ The virtual ethnographic methodology involved the research associate on the project being immersed in the day-today online and offline interactions of approximately 100 learners in three formal degree programmes spanning undergraduate and postgraduate levels in two large Scottish universities. These programmes included full-time undergraduate students in Divinity and Design Engineering and part-time postgraduate distance learners at Masters level. Data were generated from student weblogs (produced as part of the assessed element of their programme of study), wikis and course discussion boards, and also through online and offline interviews with students and teachers (see Hemmi, Bayne, and Land in press). The interviews took place across a range of environments including online chat, Second Life, telephone and face-to-face sessions. Additional data given here effectively extend this project, being drawn from the textual and thematic analysis of weblogs and discussion board postings of students on the University of Edinburgh's MSc in E-learning. ${ }^{3}$ The students quoted here are all mature postgraduates, and are in general describing experiences as relative newcomers to virtual worlds.

\section{Scenes of the uncanny}

What do we mean when we talk about the 'uncanny'? Though the uncanny can create fear, it is something which goes beyond the simply frightening:

\begin{abstract}
The uncanny is ghostly. It is concerned with the strange, weird and mysterious, with a flickering sense (but not conviction) of something supernatural. The uncanny involves feelings of uncertainty, in particular regarding the reality of who one is and what is being experienced. Suddenly one's sense of oneself ... seems strangely questionable. ... It is a crisis of the natural, touching upon everything that one might have thought was 'part of nature': one's own nature, human nature, the nature of reality and the world. But the uncanny is not simply an experience of strangeness or alienation. More specifically, it is a peculiar commingling of the familiar and unfamiliar. ... As a crisis of the proper and natural, it disturbs any straightforward sense of what is inside and what is outside. The uncanny has to do with a strangeness of framing and borders, an experience of liminality. (Royle 2003, 1)
\end{abstract}

Freud's essay on the theme, originally published in 1919 as 'Das Unheimliche' (literally, the 'unhomely'), constructs the psychology of the uncanny in terms of the way in which it involves the return of something long repressed, which was once familiar. These may be childhood complexes, or the "remnants of animistic mental activity" (Freud 1919/ $2003,147)$ - hangovers from an earlier stage of cultural development in which the return of the dead, the supernatural, and the strangeness of other parallel worlds were believed in as real possibilities, in a way which contemporary accounts of the rational have disallowed.

Freud describes several situations in which the uncanny might emerge, which connect well with Royle's account quoted above: the fear of death and ghosts; the questioning of the 
nature of the human inherent in instances of animation and automation; the questioning of the nature of selfhood which emerges via the theme of the 'double' or doppelganger; and most crucial to the argument presented here - the association of the uncanny with the theme of intellectual uncertainty and the blurring of the boundary between fantasy and reality. It is not hard to see here the link with virtual worlds and the ways of being they embody. In the section which follows, I will expand briefly on each of these themes, connecting them with quotes from students which hint at the 'uncanniness' of the learner experience of virtual worlds.

\section{Death and ghostliness}

"To many people," Freud tells us, "the acme of the uncanny is represented by anything to do with death, dead bodies, revenants, spirits and ghosts" (148). In the research described here, it was striking how regularly the theme of 'deathliness' emerged in student accounts of entering and negotiating virtual worlds (in this case, generally Second Life). The quote from Eleanor with which I began this paper described the 'corpse'-like nature of the avatar in which identity, and even desire, is artificially normed by the technological environment. Here, the avatar is constructed as zombie, as a carcass re-animated in the interplay between user and environment. For other students, the experience of entering the virtual world is itself like one of dying. In the quotes that follow, Margaret describes her experience during an induction session in Second Life run as part of the MSc in E-learning at Edinburgh, while Maisie reflects on identity issues in the virtual world as part of an end-of-course assignment:

Sometimes trees block my view and I can't see where I am. It almost felt like a blind person moving around in an unknown territory without the white stick. Since our meeting place was so close to the sea I was really worried of drowning because of this time delay. That is another experience that I could not even begin to describe. It truly gives you an out of the body experience with unshakable feelings of getting lost, drowning and even dying. (Margaret, weblog posting)

Virtual worlds' challenging disassociation of identity from the physical body in exchange for the graphic or text media of the screen can seem at best like going inside a cartoon and in the worst of cases like going through a type of physical death only to awake in the other world with all of one's senses intact. (Maisie, essay extract)

For Cara, however, 'ghostliness' emerges in quite a different way, being more to do with the opportunities for embodied, real-life 'lurkers' to be present in Second Life yet invisible - 'looking over the shoulder' of the user at the keyboard:

Embodied people can't lurk - they have presence. However, it occurred to me afterwards that there may well be disembodied lurkers in SL, as we show our RL colleagues what is going on on screen. I've done this a couple of times. I didn't do it during our tutorial, but I might have - and now I'm questioning the ethics of this. (Cara, weblog posting)

In the kind of reversal which is typical in the operations of the uncanny, the 'ghost' here becomes, not the avatar as in Eleanor's account, but the real-life person - the living body of the 'colleague'. The theme of ontological disorientation which pervades these accounts extends across each 'scene of the uncanny' being unfolded here, and will be returned to later in terms of its connection to the 'ontological shift' in higher education (Barnett 2005, 2007). 


\section{Animation, automation and insanity}

An "excellent case" of the uncanny, according to Freud, is one highlighted by Jentsch (1906) in his early essay on the psychology of the Unheimlich. This is to do with animation and the appearance of life in the inanimate - in some senses a return to the zombie theme, which raises "doubt as to whether an apparently animate object really is alive and, conversely, whether a lifeless object might not perhaps be animate". Freud goes on:

In this connection [Jentsch] refers to the impressions made on us by waxwork figures, ingeniously constructed dolls and automata. To these he adds the uncanny effect produced by epileptic fits and the manifestations of insanity, because these arouse in the onlooker vague notions of automatic - mechanical - processes that may lie hidden behind the familiar image of a living person. (Freud 1919/2003, 135)

The in-between status of the avatar - a 'doll' invested to some extent with the interactional and personality characteristics of the 'real' user-encapsulates in its very existence something of this aspect of the uncanny. Add to this the ability to automate movement via animation (to enable the avatar to dance, to wave, to kiss, to embrace) and the disorienting blur between life and lifelessness becomes even more foregrounded. The existence of 'bots' in-world, avatars controlled by code rather than by a living user, adds a further layer. When the animation and coding 'goes wrong' and the avatar is caught in a mechanised, repetitive loop of movement, the effect is without doubt uncanny as the appearance of contingent reality upon which our tolerance and understanding of the virtual world rests is shaken and disrupted.

The 'manifestations of insanity' associated with this aspect of the uncanny are intriguingly described in an account given by Maisie of an encounter - the time in The Palace (a 2D virtual world) - with an unknown avatar. Maisie describes staying behind in The Palace after a tutorial, to continue to chat with another student, Fiona. She describes how their chat is interrupted by a strange avatar called 'happy birthday':

We carried on talking and then it said; "I have loads of goat cheese and I want to give it to you". I thought, "What on earth is this? Is it drugs he is offering or something else? Is he just a looney?" We did not say anything. 'happy birthday' went on saying even more incoherently: "oh, Lord JJJJesus" - with repeated 'J's - "I have loads of goat cheese and it's not evil", or something like that. At that point I thought, "Oh dear, I'd better leave this place now, this is getting a bit much".

Ten or fifteen seconds went by - I had not left because I was a little 'puzzled' by all that - and then 'happy birthday', moving slightly towards us ... said: "God, save Lord JJJesus, the devil is not here, I have all of this goat cheese that I want to give to you...". Silence and then Fiona said "I don't think so". I told Fiona I would see her later and left. I was afraid!

The fact that 'it' got closer to me made me really uneasy. So uneasy, that 'I' did not even care about leaving 'Fiona' with 'it' alone. After logging out, I found the whole experience strange, unexpected and totally unbelievable! ... What I found unbelievable was the level of immersion in which my real 'I' was. In spite of having a third person view of the whole incident, the virtual being actually managed to scare the Real Maisie - to the point that she pulled her virtual representation out of the Chess Room. ... The most shocking thing for me was the impact that its language and its use of silence and space had on me. (Maisie, weblog posting)

\section{The double}

The doppelganger is perhaps one of the most pervasive and compelling instances of the uncanny, and the most indicative of the kind of ontological uncertainty we engage with 
when we work within virtual worlds. To enter the virtual world as a user (rather than as one of Cara's 'ghostly' onlookers), we are obliged to construct an avatar, to engage with the prospect of our own 'double' which, "in all its nuances and manifestations" (Freud 1919/ 2003, 141) encapsulates something of the uncanny:

This relationship [between 'self' and 'double'] is intensified by the spontaneous transmission of mental processes from one of these persons to the other - what we would call telepathy - so that the one becomes co-owner of the other's knowledge, emotions and experience. Moreover, a person may identify himself with another and so become unsure of his true self; or he may substitute the other's self for his own. The self may thus be duplicated, divided and interchanged. (Freud 1919/2003, 141)

It is perhaps in this foregrounding of the nature of selfhood that some of the most powerful pedagogical possibilities of virtual worlds lie. As one tutor commented, "If one wants to explore virtuality ... it does not seem appropriate to commit oneself to being one thing" (Michael, interview). Yet it is here that the most disquieting effects of the virtual also appear - when we work in virtual worlds, we are never entirely able to 'fix' the identity of the person with whom we are interacting. In Second Life tutorials, the identities of tutor and students are largely unconnected to their 'real life' equivalents - each member of the class is 'doubled' in a disorienting yet exhilarating context of interaction.

For some students, this sense of ontological 'play' has a profound pedagogical value. Margaret describes the experience of being metaphorically embodied in class Second Life tutorial sessions in the following way:

We like to experiment with the appearance of the avatar and through experimentation I think we can gain some understanding of who we really are. Philosophically, I think finding ourselves or who we really are, is the ultimate learning experience and all that we do in our lifetime contributes to it.

I think that the feeling of presence counts a lot in SL because otherwise it would be just like a normal chat session. It is what we do with our avatars and how we react to people and other situations that matter most in SL, I think. So I would say that our identities are more real when expressed though an avatar. (Margaret, weblog posting)

For others, it is deeply disturbing. For instance Joe, a co-student of Margaret's, describes the basis of an unease with virtual worlds in terms of cultural specificity and religious belief:

The appearance of an avatar may sadly be a 'put-off' for those with which it interacts. Our perception of attractive and acceptable varies quite a lot and colour mix of 'clothing' or type of face chosen by one (avatar) may put the other off and lead to creation of 'dislikes'. Choice of animal heads for avatar faces may send a terribly wrong message in my culture. Such an avatar may be considered a sorcerer or witch/wizard. Who would want to interact with such a 'person'?

There is also some possibility of offending some people's religious inclination, e.g. suggesting idolatry. The Bible ... teaches that we are made in God's image and if one adopts the image or looks of an animal then s/he is adopting the image of an idol hence s/he is practising idolatry! It is even worse in cases where a person considers the animal face to represent their identity better than their real face. (Joe, weblog posting)

Both Margaret and Joe comment on the notion of the 'double' or the representation gaining a reality-status in the mind of the user which is greater than that of the embodied self. The 
relation between 'copy' and 'original', 'self' and 'double' is thoroughly disturbed. For Margaret, this is a valued and profound aspect of avatar pedagogy. For Joe, it is a deeply problematic instance of the challenge the virtual world might pose to existing religious belief.

\section{Intellectual uncertainty}

The final scene of the uncanny which I wish to explore here is the one which is perhaps most crucial to the arguments which follow. This is the notion of the uncanny - proposed by Jentsch (1906), questioned by Freud (1919/2003), but highlighted as central by later theorists (for example Royle 2003; Haughton 2003) - as being to do with intellectual uncertainty and the disquietude which occurs when "the boundaries between imagination and reality are erased" (Kristeva 1991, 188).

The strange, dream-like nature of the virtual world, in which reality and imagination become inseparable, was commented on by several students. The following students all describe their early experiences with Second Life, prior to formal tutorial sessions on the MSc in E-learning:

[1:00] Dark Roly: Its really weird,

[1:00] You: Second life?

[1:01] Dark Roly: Yes. Its fun but sort of weird, I can see why it becomes addictive.

[1:01] You: In what way d'you find it weird?

[1:02] Dark Roly: Communicating via an avatar, sort of real and not real all at the same time. (Dark, conversation in-world)

The wind sounds in the background tend to make it feel like this is a dream or at least all happening in your head. When someone makes a sound then it really stands out like a banshee wailing in the night. (Simon, weblog posting)

On Tuesday evening (night before last) I went on to Second Life (or should that be *into*). It loaded fine at five o'clock and [my children] changed my clothes for me, so they now no longer believe that this course is hard work and want to know when they can come to play in Mummy's dreamworld as they call it. (Gillian, weblog posting)

Key to understanding this aspect of the uncanny is the idea that in the blurring of the boundary between fantasy and reality the relation between the sign (in our case, the avatar) and what it apparently signifies (the selfhood of the user) shifts and becomes problematic. Kristeva (1991), quoting Freud (1919/2003, 150), describes this well:

What brings together all these symbolic processes ... lies in a weakening of the value of signs as such and of their specific logic. The symbol ceases to be a symbol and "takes over the full function of the thing it symbolizes". In other words, the sign is not experienced as arbitrary but assumes a real importance. As a consequence, the material reality that the sign was commonly supposed to point to crumbles away to the benefit of imagination, which is no more than "the over-accentuation of psychical reality in comparison with material reality". (Kristeva 1991, 186)

In other words, the 'uncanniness' of the avatar may rest partly in its tendency to be perceived as "taking over the full function" of the real-life user and his or her embodied selfhood. The 
'psychical reality' of the avatar becomes privileged above the 'material reality' of the user. This, in turn, relates back to the ontological anxiety foregrounded in many of the student accounts presented here and engages in the notion of intellectual uncertainty surrounding the nature of being in the virtual world. For Jentsch, it is this intellectual uncertainty which is "the essential condition for the emergence of a sense of the uncanny" (Freud 1919/2003, 125).

I wish now to expand on this theme of intellectual uncertainty, by exploring ways in which the strange, the troublesome, the ontological, the uncertain - in fact, the uncanny can be seen to be integral to the idea of a 'genuine' higher education.

\section{The 'uncanniness' of higher education}

In exploring the possibility of a theory of 'haunted teaching', Royle (2003) - drawing on Freud and the notion of the uncanny - describes the pure necessity of intellectual uncertainty as the basis of a high quality university teaching:

Intellectual uncertainty is not necessarily or simply a negative experience, a dead-end sense of not knowing or of indeterminacy. It is just as well an experience of something open, generative, exhilarating (the trembling of what remains undecidable). I wish to suggest that 'intellectual uncertainty' is in part what Freud's essay has to teach and, indeed, that this is a crucial dimension of any teaching worthy of the name. (52)

The ontological uncertainty foregrounded in the student accounts given here perhaps simply indicates that Second Life and other virtual worlds materialise this uncertainty in new ways - they defamiliarise our sense of selfhood and our mode of being together within the pedagogical context, and in doing so ask us to reflect on it afresh as teachers and learners.

Barnett's (2007) text, subtitled 'Being a Student in an Age of Uncertainty', highlights the centrality to the contemporary student of the kind of intellectual indeterminacy described by Royle. For Barnett "the uncertainty principle reaches deeply into the student's being" (127), and one of the prime goals of a genuine higher education must be to help students become able to accept and live in a positive way with the kind of intellectual uncertainty which is integral to a life informed by academic ways of thinking and practising.

Such a way of thinking is almost inevitably uncomfortable and anxiety-inducing. Indeed, for Barnett, "a pedagogical achievement of higher education is that - on the student's part - of coming to live purposefully with anxiety" (36, original emphasis). A connection might be made here with the notion of 'troublesome knowledge' described by Perkins $(1999,2006)$ - the "ritual knowledge, inert knowledge, conceptually difficult knowledge, foreign knowledge, and tacit knowledge" $(2006,37)$ which may induce in students a sense of anxiety and disorientation, appearing "counter intuitive, alien ..., or incoherent" (Meyer and Land 2006, 9). For Meyer and Land, such troublesome knowledge is itself implicated in the notion of 'threshold concepts', which suggests that there is an ontological dimension to the way in which students come to negotiate - though not necessarily resolve - such areas of difficulty and uncertainty. In negotiating a threshold concept, the perception of the student undergoes a "significant shift ... [which] may lead to a transformation of personal identity, a reconstruction of subjectivity" (7). To cross such a threshold is to experience the kind of liminality which Royle $(2003,1)$ sees as central to the experience of the uncanny (Meyer and Land 2005).

The terms emerging, therefore, in recent accounts of the process and purpose of higher education - haunted teaching, troublesome knowledge, risk, anxiety, thresholds, liminality, uncertainty - might incline us towards an understanding of contemporary higher education 
as itself incorporating something of the uncanny. For Barnett (2007), in fact, the ontological dimension of studenthood implicitly and explicitly involved in such terms is absolutely central to an understanding of what it means to conduct higher education in the twenty-first century. Higher education, he argues, is "in urgent need of an ontological turn" (26), an understanding that "a genuine higher education is none other than a transformation of being" (38). In an age of rapid change, in which all knowledge is conceived as contestable and contingent, such transformation must be in terms of "the taking on of a mode of being for uncertainty" (39).

To teach, therefore, is to engage with new ontologies which make students 'strangers to themselves' (Kristeva 1991), to immerse students in worlds of uncanny strangeness:

The student is perforce required to venture into new places, strange places, anxiety-provoking places. This is part of the point of higher education. If there was no anxiety, it is difficult to believe that we could be in the presence of a higher education. (Barnett 2007, 147)

\section{In conclusion: virtual worlds and the 'pedagogy of uncertainty'}

As this paper has attempted to demonstrate, virtual worlds can, for some students, themselves represent such worlds of strangeness - they can be uncanny spaces, in which new, anxiety-provoking yet rich understandings of the nature of being in a digital age can be confronted. In some senses, the virtual world literalises the metaphorical and cognitive 'strangeness' and 'troublesomeness' which some of the most interesting accounts of contemporary higher education describe.

I do not suggest here that virtual worlds must be the primary location of a new higher education which is concerned with the ontological. My argument is rather that such spaces can be used with some students, in some contexts, as a way of working productively with the 'strangeness' and 'uncanniness' of contemporary academic - and digital - ways of being. In such alluring, difficult, problematic spaces we might have new opportunities to nurture what Barnett refers to as a "pedagogy for uncertain times":

A pedagogy for uncertain times has itself to be uncertain. It is open, it is daring, it is risky, it is, itself, unpredictable ... A pedagogy for uncertainty will be ontologically disturbing and enthralling all at once. It will be electric, as one move sparks another and in unpredictable ways ... This pedagogy is a form of restrained anarchy; even a disciplined anarchy - with its spaces and its risks. $(2007,137)$

\section{Notes}

1. All student names have been changed.

2. Thanks to Professor Ray Land and Dr Akiko Hemmi, collaborators on the HEA project, for allowing me to use the data here.

3. Many thanks to the students on the MSc in E-learning at the University of Edinburgh, who so generously allowed me to use their words here.

\section{References}

Arnzen, M. 1997. Introduction. The return of the uncanny. Paradoxa: Studies in World Literary Genres, Special Issue, 3, nos. 3-4.

Barnett, R. 2005. Recapturing the universal in the university. Educational Philosophy and Theory 27, no. 6: 785-97.

2007. A Will to learn: Being a student in an age of uncertainty. Buckingham, UK: Society for Research in Higher Education and Open University Press. 
Carrington, V. 2005. The uncanny, digital texts and literacy. Language and Education 19, no. 6: 467-82.

Castle, T. 1995. The female thermometer: Eighteenth-century culture and the invention of the uncanny. Oxford: Oxford University Press.

Freud, S. 1919/2003. The uncanny. London: Penguin Classics.

Grenville, B. 2002. The uncanny: Experiments in cyborg culture. London: Arsenal.

Haughton, H. 2003. 'Introduction' to Sigmund Freud. In The uncanny, vii-lx. London: Penguin Classics.

Hemmi, A., S. Bayne, and R. Land. In press. The appropriation and repurposing of social technologies in higher education. Journal of Computer Assisted Learning.

Jentsch, E. 1908. Zur psychologie des Unheimlichen. Psychiatrisch-neurologische Wochenschrift 8: 195-205.

Johnson, C. 1999. Ambient technologies, uncanny signs. Oxford Literary Review 21: 117-34.

Kristeva, J. 1991. Strangers to ourselves. London: Harvester Wheatsheaf.

Meyer, J.H.F., and R. Land. 2005. Threshold concepts and troublesome knowledge (2): Epistemological considerations and a conceptual framework for teaching and learning. Higher Education 49, no. 3: 373-88.

. 2006. Threshold concepts: An introduction. In Overcoming barriers to student understanding: Threshold concepts and troublesome knowledge, ed. J.H.F. Meyer, and R. Land, 3-18. London: RoutledgeFalmer.

Mori, M. 1970. The uncanny valley. Energy 7, no. 4: 33-5. http://graphics.cs.ucdavis.edu/ staadt/ ECS280/Mori1970OTU.pdf

Perkins, D. 1999. The many faces of constructivism. Educational Leadership 57, no. 3: 6-11.

2006. Constructivism and troublesome knowledge. In Overcoming barriers to student understanding: Threshold concepts and troublesome knowledge, ed. J.H.F. Meyer, and R. Land, 33-47. London: RoutledgeFalmer.

Ramey, C.H. 2005. The uncanny valley of similarities concerning abortion, baldness, heaps of sand, and humanlike robots. In Proceedings of Views of the Uncanny Valley Workshop: IEEE-RAS International Conference on Humanoid Robots, Tsukuba, Japan, 8-13.

Royle, N. 2003. The uncanny. Manchester: Manchester University Press.

Tie, W. 2004. The psychic life of governmentality. Culture, Theory and Critique 45, no. 2: 161-76.

Weight, J. 2006. I, apparatus, you: A technosocial introduction to creative practice. Convergence: The International Journal of Research into New Media Technologies 12, no. 4: 413-46. 